Chapter 2

\title{
Sociohistorical and cultural context of Late Modern English Medical Texts
}

Irma Taavitsainen, Peter Murray Jones, and Turo Hiltunen

The eighteenth century presents as a transition period towards more modern practices in medical history. In this chapter we probe into these developments as reflected in medical writing and provide a sociohistorical overview of background for the corpus. When compared to the earlier phases of medical writing in England, the sheer number of texts in the vernacular grew enormously while readerships with the ability to read and learn about medical issues widened, making it possible for medical knowledge to reach new layers of society. The ways of writing science were also changing: the beginning of the Royal Society period had been a period of innovation in cutting-edge science in communicating new discoveries. These practices continue in the learned circles, but polite society favoured more rhetorical styles, and the scholastic tradition was also present. Our approach is sociopragmatic as we focus on variation in texts to different audiences, and all observations are contextualized with qualitative discourse analysis. Significant changes were taking place both in the underlying philosophy of science and its applications, e.g. statistical assessments emerged, paving the way to evidence-based medicine.

\section{Towards a diachronic view of medical thought styles}

To understand the present, and no doubt to foresee the future, we must take a long and comparative historical view. (Crombie 1995: 225)

Language is the main medium through which knowledge of medical practices in the past is mediated to us. Science, including medicine, is one of the major activities of our minds, and it may be regarded as a mood in which we consider our world. ${ }^{1}$ The formation of conventions of medical writing reflects the search for the underlying facts of human life from the medical viewpoint, how sicknesses affect people, how they are treated and possibly cured, and how health can best be maintained. Definitions vary according to the time period concerned, but the fundamental issues of life and death remain, regardless of whether health is defined as a balance of humours, the proper functioning of bodily mechanisms, or the absence of illness.

\footnotetext{
' This definition is taken from Encyclopaedia Britannica (1966) s.v. 'science'. The more recent edition gives a different definition.
} 
In this chapter, we introduce the sociohistorical frame of the corpus of Late Modern English Medical Texts 1700-1800 (LMEMT), a new resource for studying the language of medicine in the eighteenth century, and we shall offer a brief account of the multifaceted culture in which its texts were communicated. Our approach in this book can best be described as sociopragmatic, in that all observations and quantitative findings are presented together with careful contextualization and qualitative analysis. Quantitative assessments are primarily used to determine the main lines of development in medical argumentation that deserve further attention. Our interpretations draw on multi-layered contextual information and sociolinguistic parameters of authors and audiences of these texts.

Our approach in this book is in line with current trends in historical (socio)pragmatics with its interdisciplinary and methodologically eclectic research ground (see Wlodarzyck and Taavitsainen 2017: 163-166). The sociopragmatic approach to language use is an inter- and cross-disciplinary endeavour that aims at placing linguistic data from the past in societal and cultural contexts of the period. Various emphases are possible. Leech (2014) brings politeness concerns to the forefront and so does Culpeper (2009). ${ }^{2}$ Our focus is somewhat different as we place the emphasis on cultural aspects with the prevailing worldview and ways of understanding the human body, health and sickness, and how people dealt with medical issues in various types and genres of communication. Our main research questions deal with linguistic realizations of medical texts and discourse strategies, with a special focus on how language use in medical texts reflects underlying scientific thought styles (see note 51 in Chapter 3 and Taavitsainen 2017). Such research questions can be pursued on different levels of linguistic analysis from the macro level of genre conventions and their diachronic developments to the micro level of individual linguistic features. Combined together, they can yield a more complete picture of the developments. Local meaning-making practices often involve both generic and specific aspects of language use: conventional phrases and collocations, personal pronouns expressing the personal viewpoint and

\footnotetext{
2 Leech (2014: 14) defines the field in terms of various scales of value that make a particular degree of politeness appropriate or normal in a given situation between text participants, involving both horizontal and vertical distance between the speaker and the addressee, and the weightiness of the transaction. Culpeper (2009: 181) specifies three foci in sociopragmatics: situated roles and identities; relational work, power, social distance and affect; and attitudes and opinions.
} 
other deictic features like address terms to anchor language use to particular situations. They involve politeness in professional communication and interaction between text participants; these aspects of language use receive due attention in the studies of this volume. The value of historical (socio)pragmatics lies not only in in-depth accounts of the multiple facets of contextual information underlying discourse features, but essentially the analysis goes beyond the textual level to make interdisciplinary connections. We would like to acknowledge the contribution that other fields make to the study of language use in this volume: historical developments as outlined by medical historians in their studies on e.g. prevailing and changing medical doctrines, and scientific thought styles form the basis of many of our linguistic assessments. The advent of digital humanities is also worth mentioning here as we can gain a more solid grasp of the issues under scrutiny with computational methods. They can help us find new answers to our research questions when the results are complemented and interpreted by qualitative discourse analysis.

We see eighteenth-century medical writing as a period of transition from earlier practices towards more modern approaches. This is apparent, for example, in the development of case reports: accounts of individual patients start evolving into surveys of courses of illness based on several manifestations and their outcomes, leading gradually to probabilities in prognosis (see Chapter 5 in this volume). The main object of our studies is, however, language use and linguistic practices through which medical English developed towards its present form. ${ }^{3}$ The historical perspective gives depth to our linguistic perceptions on medical communication. The importance of a collection of medical texts that is as comprehensive and representative as possible for historical linguistic research can hardly be overstated, as a full understanding of current practices is only possible if we understand how the features of medical writing have come about, and if we know what the past conventions were and can relate them to the changing thought styles of the period. Medicine has rightly been seen as having a special status among scientific disciplines: its knowledge basis, once established, was claimed to be vitally relevant to human wellbeing not just for each individual citizen, but for society as a whole. Like law or theology, it represented one of the disciplines of university study in high regard, but was seldom at the cutting edge of new knowledge. In addition,

\footnotetext{
${ }^{3}$ The present position of English as a lingua franca of science is fairly recent. French and German were strong candidates, but English started to dominate in the 1950s and 60s (see Taavitsainen 2006).
} 
it had a practical side, and medical advice was sought after by all classes of society, but its forms and contents vary; this is an important point as our focus is on language practices in communicating medical knowledge in context of different situations, authors, and audiences.

\section{Changes in eighteenth-century medical writing in England}

An important change towards modern practices took place in the ways of disseminating and communicating medical knowledge in the course of the eighteenth century. Besides monographs and the general scientific journal The Philosophical Transactions (PT 1665-), specialized periodical journals were established in the 1730s including those that are customarily grouped together under the title of the Edinburgh Medical Journal (EMJ; see the category description in this volume). They resemble modern practices in that the publication process was swift; PT had started this practice already in the previous century so that the findings of empirical research were delivered to the Royal Society within a short time span. Reports were printed soon after the experiment had been conducted and thus the research community could initiate discussion without delay. The eighteenth century also witnessed the founding of The Gentleman's Magazine (GM 1731-1922), the first general magazine targeted at educated lay readers from polite society (see Chapters 7 and 9 below in this volume). The magazine published articles, news and letters and reprinted newspaper items dealing with medical issues mainly for the benefit of the lay public, but also for the information of medical doctors; this two-way traffic was characteristic of the period. ${ }^{4}$ The audience was, however, limited to the social elite, and the first industrialized forms of mass communication did not appear until the early nineteenth century (Conboy 2017).

At the same time, significant changes were taking place both in the underlying philosophy of science and its applications. In terms of theoretical dominance, Newtonian natural philosophy overshadowed medicine insofar as it established paradigms of method in knowledge acquisition. By describing some subset of phenomena that could be interrogated by empirical methods of investigation as part of a whole, it aimed at developing a logically consistent theoretical model, based on a

\footnotetext{
${ }^{4}$ The signatures of the Letters to the Editor include medical doctors. The close interaction between the faculty and educated lay people provided feedback and contributed to the development of medical practices (Jewson 1974).
} 
certain set of philosophical assumptions about the way of the world. This model is echoed in the words from one of the early authors in LMEMT:

(1) Because Experience is equally the Foundation and Touchstone of all reasoning in Physick, we will here submit our Solution to common Observations, and try whether every thing proposed in it, does not exactly answer Matters of Fact, and the visible Operations of Nature.

(Cockburn, The practice of purging and vomiting medicines, 1705: 2)

But there were further developments in the eighteenth century. Most importantly, this period saw the advent of the first statistical assessments that started to shift the knowledge basis, paving the way for modern evidence-based medicine. The new basis can clearly be seen e.g. in the debates pro and con of the inoculation conflict, where probabilities were calculated and brought forth in argumentation in a newspaper already in the early 1720s (see below). The author considers seven cases too few, which shows that the new way of thinking was fairly widespread:

(2) Sir,

I have read Dr. Brady on Inoculation, which you sent me, and instead of being in the least convinced, ... surprised that any one could have the Assurance to write on a Subject, when he was entirely ignorant of Facts, and had seen but seven, ...

(The Evening Post, London, August 30, 1722)

The eighteenth century saw some other fundamental changes in medical practices as well. Experiments and verifiable facts laid the basis for further enquiry, and the topics of medical texts became more varied, giving evidence of a new phase in medical writing (see Chapter 3 in this volume). In addition, the scope of medical literature became wider as patients recorded their experiences of illnesses more extensively than before, selfcultivation began to appear as an ideology, and medical consultation by correspondence flourished. ${ }^{5}$ The world had widened at the break of the early modern period, bringing exotic materia medica like Peruvian bark to Europe with Spanish and Portuguese traders (see e.g. Grafton et al. 1992). Before the mid-seventeenth century, the overseas

\footnotetext{
${ }^{5}$ Biographer James Boswell (1740-1795), for example, kept a diary including subjective details of health and sickness (ODNB 2004; Thurnbull, s.v. 'James Boswell'). Several contributions to GM from its readers contain short autobiographical narratives. For medical correspondence, see Wild (2006) and Brown (2011).
} 
activities of the British were local affairs with a focus on trade and exploration, but by the eighteenth century powerful naval supremacy had expanded the reach of the British Empire to profitable global extension from sunrise to sunset (Levine 2013). ${ }^{6}$ Foreign climates and long voyages brought new health issues into medical discussion; attention was paid to seamen's dietary problems and new imported articles for consumption, such as tea, led to worries about their health effects (see GM description in this volume). At the same time, societal attitudes towards the sick and the poor were generally changing in Britain and philanthropic ideas were spreading, giving incentives to charitable actions: the first voluntary hospital was founded in London in 1720 (Digby 1994: 3), and many more were established by the end of the century.

Edinburgh University (and to a lesser extent other Scottish universities) became a leading centre for medical education, attracting students from England and from other European countries; by comparison, Oxford and Cambridge were of far less importance for advanced medical teaching (Broman 2003: 465). London retained its crucial medical importance because of its institutions: the Royal College of Physicians (1518), the Company of Surgeons (1745-) and the Society of Apothecaries (dating from the seventeenth century). Alongside these, new medical societies were established, and activities connected with medicine flourished, with anatomical theatres and such industries as instrument making growing in number. The role of London was also increasing as the hub of international trade in materia medica. The Industrial Revolution in the mid-century brought more people to towns, and provincial cities like Bristol, Manchester, and Birmingham were also thriving as medical centres in the eighteenth century in part because of new voluntary hospitals, local medical societies, and active local printing presses, which turned out medical advertisements and handbills in considerable quantities (although not many survive to the present).

\section{Medical communication, literacy, and vernacularization}

During the century in focus, modes of medical communication became more diversified and new topics emerged. When compared to the earlier phases of medical writing in England, the sheer number of texts in the vernacular grew enormously while audiences

\footnotetext{
${ }^{6}$ The eighteenth century has as a result of the slave trade been characterized as the era of British Atlantic dominion (Levine 2013).
} 
with the ability to read and learn about medical issues widened, making it possible for medical knowledge to reach new layers of society. Books, journals and newspapers were the main media of communicating medical matters. Our focus is on printed data, but texts were also circulated in manuscripts, and oral transmission of received knowledge continued especially among the illiterate.

Levels of literacy across eighteenth-century England form part of the sociohistorical background that is essential for interpreting the language use of medical texts. During the eighteenth century, literacy increased and spread to larger proportions of the population. Variation is considerable: Wear concludes his survey of literacy developments between 1500 and 1700 by stating that "half of the population was probably illiterate in 1750" (1992: 18). Literacy skills varied regionally, too. In the more developed urban centres of the country, the rates of literacy were as high as some 60 or even 70 per cent, while remote rural areas remained at a low level. Male literacy increased in the higher social groups, including the gentry, yeomen, merchants, and shopkeepers, while husbandmen, poor artisans, labourers and servants remained mostly illiterate (Brooks 1995: 76). Importantly, women were only taught to read but not to write (Wear 1992: 17). The levels of literacy varied along several other axes, too, such as vernacular and Latin literacy, religious and secular, public and private, institutional and domestic (see Jones 2011). In addition, a secular print culture of vernacular newspapers and magazines was instrumental in the creation of new cultural modes in the eighteenth century (see Collins and Blot 2003: 71).

The LMEMT corpus represents medical writing in English and consists of several layers, corresponding to different audiences and levels of literacy. The top layer consists of learned and sophisticated writings by highly educated authors targeted at their peers, but we have texts for other audiences as well, including writings for ordinary households and heterogeneous people. Lay authors also contributed to the variety of writings, though this group is fairly small in our corpus. Most texts were written either in London or Edinburgh.

In the eighteenth century, the history of English medical writing covered several hundred years, as vernacularization of medical and scientific texts had already started in the late medieval period (c. 1375-) as part of the pan-European phenomenon, first with some spearhead surgical texts and learned specialized treatises (see MEMT 2005; 
Pahta and Taavitsainen 2004). Remedybooks with recipes and prognostications had even longer roots in the vernacular, with traditions deriving from Old English and continuing at least up to the late modern period. The transition period between the late medieval and early modern lasted for a long time. Old texts continued to be copied by hand in manuscripts and provided material for printing in books. Humoral medicine had long afterlives in various applications for centuries (see Taavitsainen 2018). Original compositions started to appear in mid-sixteenth century, but were still rare. The rise of English empiricism and the founding of the Royal Society in 1662 marked the beginning of new developments, with conscious attention to language issues (see the next section). A turning point in the process of vernacularization has been placed at c. 1700 (Webster 1975; Crossgrove 1998: 83) and in this respect, the eighteenth century represents a new era. Yet, publication records show that the process by which English replaced Latin in medical publications continued and was not completed for a long time. Changes were gradual, especially as Latin remained the international language of scientific communication throughout Europe. In the first quarter of the eighteenth century, medical treatises were still written in Latin in England, and educated authors continued to communicate in Latin in several contexts. A good example is John Friend (1675-1728), who was educated amongst the great classical scholars of Westminster School (ODNB 2004; Dahl, s.v. 'John Friend'). While Latin was the language of his Emmenologia (1703) on menstruation, he contributed to The Philosophical Transactions in English, and also wrote a pioneering History of Physick (1725-1726). By the second quarter of the eighteenth century, original English medical texts already outnumbered those in Latin, but Latin continued to play a significant role in the technical vocabulary of anatomy, surgery, and materia medica. Excerpts from Latin texts were common in some writings on medical institutions (see PUBLIC HEALTH category description), and Latin was a favourite source of mottoes for medical title pages even in texts for lay readers. ${ }^{7}$ In this way, highly learned authors writing in English signalled their command of classical knowledge, and at the same time this practice bears witness to the continuing prestige of Latin as a language of learning. Nevertheless, even an ardent Latinist like John Freind would accept the case for writing

\footnotetext{
' George Cheyne, for example, included a reference to Hippocrates and Celsus in a quotation on the title page of his Essay of health and long life (1724).
} 
some of his own work on medical subjects in English as the best means of addressing his contemporaries and furthering the health interests of the public.

Some authors like George Wallis openly deal with the language issue even this late, defending the use of the mother tongue, as was customary in earlier centuries:

(3) ... the brightest luminaries of the Hippocratic school, have not disdained to convey their discoveries to the world in the common language of this country - a language, if not esteemed so concise and elegant, yet full as comprehensive, full as replete with descriptive powers, as any of which Greece or Rome could ever boast; and as it must be allowed, that opinions in any art ought to be delivered in modes divested of all ambiguity and embarrassment, certainly, considering our own vernacular language possessed of these advantages, as being the most familiar to a very great majority of this audience, though learned.

(Wallis, Annual oration, delivered March 8th, 1790, 1790: 1-2)

This quotation resembles the apologetic arguments for writing in the vernacular presented centuries earlier in the late medieval and early modern periods (see McConchie 1997), but some of it can also be read in a different way, expressing pride in the "descriptive powers" that the English language had achieved. By the time of Wallis's publication, the hegemony of the English language in scientific and medical texts had consolidated to the extent that it was the means that most medical authors chose as their vehicle of communication, though they could revert to Latin for special purposes. ${ }^{8}$

\section{Authors and audiences}

People with their varying "horizontal and vertical distances" (as Leech 2014: 129 puts it) play a crucial role in interpretations of linguistic features in sociopragmatics. In medical writing the patterns may be less varied than in fiction, for example, but an awareness of the background sociolinguistic parameters is essential to achieve a full

\footnotetext{
${ }^{8}$ Multilingualism has been a rising topic in the recent literature. For Late Modern English, see e.g. Tyrkkö and Nurmi 2017.
} 
picture of what is going on in written communication in these texts. The upper layers of society are well represented in our corpus, as many of the LMEMT texts are written by university-educated medical doctors for their peers. In these cases the vertical distance is minimal, but the politeness code of professional interaction required using the deferential address terms $D r$. And $M r$. in professional interaction (see Chapter 3 in this volume). Novices in the field were also catered for by textbooks. In contrast, some texts are written for the benefit of lay people, and then the style may be more relaxed due to audience accommodation (Bell 1984), which influences the choice of linguistic features in texts. Experienced medical practitioners wrote treatises and textbooks in their field (see the GENERAL TREATISES category description), but some authors came from completely different walks of life, such as John Wesley, founder of Methodism, also wrote on electricity in medical treatment (The Desideratum: Or, Electricity made Plain and Useful 1790). In addition, there were lay authors without formal education, but not many.

Women played an important role in households in the care of the sick (see Chapter 4 in this volume). Domestic target audiences are most notable in the categories of recipes and health guides, but also in children's diseases, where William Buchan's innovative and popular volume Domestic medicine (1769) provides a case in point. Women's contributions to medical literature are most important in MEDICAL RECIPE COLLECTIONS and in MIDWIFERY, which had traditionally been a woman's realm but the situation changed in the eighteenth century with men-midwives (see the category descriptions).

The lower end of the scale in medical literature consisted of more ephmeral texts of which a great part has been lost. Literature aimed at less educated people includes reprints of publications from earlier times, but this form of writing remains largely uncharted.

The borderlines between different types of writing are, however, fuzzy and permeable. An good example of this state of affairs in a text of a woman who allegedly gave birth to rabbits in A short narrative of an extraordinary delivery of rabbets (St. André 1727). On the one hand, this case report is connected with the scientific debate whether a species can give birth to another species (see the category description), and the text itself employs a strategy favoured by Royal Society empirical science as it records authoritative eye-witnesses to the event to convince the reader. On the other hand, the narrative can be regarded as a sample of "wonder literature" as it relates a 
strange event related to monstrous births, a popular topic in medical literature both in scientific journals and in works of popular medicine like Aristotle's Masterpiece, which has a whole section devoted to such curiosities of nature (see Taavitsainen 2012: 149150 and 2017: 264).

\section{Royal Society guidelines versus polite society styles}

The seventeenth century was a period of stylistic innovation in the spearhead genres with journal articles and academic monographs leading the way. The Royal Society style had started in the latter half of the seventeenth century, and new stylistic trends became conventionalized especially in experimental essays in The Philosophical Transactions (1665-). First-person narration was employed to present experiments in chronological stages, including hedges and cautious conclusions. It was also important to record the names of those present as witnesses of what had happened, according to the new empirical thought style. Some of the ensuing developments, such as the genre of empirical essays, have been discussed in detail in the earlier literature. ${ }^{9}$

Texts were circulated among members of the close-knit discourse communities, such as the Royal Society of London. Detailed reports of the experiments were meant to facilitate their replication, or make repeating the experiment redundant altogether, as accuracy and detail would create an impression of "virtual witnessing" of the experiment (Shapin and Shaffner 1984: 60). Several specialized journals were established during the eighteenth century. Journals became important publication media and part of the larger pattern of development towards more professionalized practices; our selection of texts opens up the possibility for more detailed assessments, as the data in previous studies is limited. ${ }^{10}$

The Royal Society put writing styles at the heart of their programme for advancing knowledge. In The History of the Royal Society of London for the Improving of Natural Knowledge (1667), Thomas Sprat had already observed that language issues and the

\footnotetext{
9 See e.g. Bazerman (1984), Berkenkotter and Huckin (1995), Atkinson (1999), Moessner (2006, 2009), Gotti (2001, 2003, 2005), and Banks (2017).

${ }^{10}$ Monographs of this period have not been studied for their stylistic features either, but we know from earlier studies that interactional styles increase towards the end of the early modern period (Taavitsainen 1999). This trend seems to continue in the eighteenth century as several authors, such as John Armstrong (1735), write in a dialogic style (see Examples (4) and (5) in the GENERAL TREATISES category description).
} 
style of writing were topics "about which the Society has been most solicitous" (Sprat 2003 [1667]: 111). The Royal Society advocated its own "plain” style for reporting observations and it also discussed the issue of a universal language. ${ }^{11}$ Programmes for good linguistic practice in the latter half of the seventeenth century originated in the new "gentlemanly" institutions of natural philosophy, and institutional guidance from above banned features like double negation (see Chapter 9 in this volume). The main concern was to report on knowledge gained from observation and experiment in a lucid way. Sprat's History advocates this goal and claims that "eloquence ought to be banish'd out of all civil Societies" (Sprat 2003 [1667]: 111). As a remedy in the same passage, and authorized by the Royal Society, he suggests rejecting rhetorical devices, going "back to primitive purity, and shortness". The desired result was described in a well-known and often cited statement as:

(4) a close naked, natural way of speaking; positive expressions; clear sentences; a native easiness; bringing all things as near the mathematical plainness, as they can: and preferring the language of Artizans, Countrymen, and Merchants, before that, of Wits, of Scholars.

(Sprat 2003 [1667]: 113)

This was the goal, but to what extent it served as a real guideline and how long it remained the ideal remains to be verified. The LMEMT corpus can help us determine the reach of the Royal Society's rules in relation to actual writing practices. The overall picture is complicated, as opposite traits emerged as well: double negatives are present in LMEMT texts, discourse structures show an underlying influence of classical rhetoric, and quotations from wits and scholars mark points of eloquence. Some texts have quotations that display carefully devised rhetorical structures. A case in point is John Anderson's text on sea bathing (1795), where he cites Shakespeare and other literary authors to culminate and condense the arguments of his medical treatise:

(5) If it was not capable of doing harm, it would be incapable of doing good. In those simples which dwell the most virulent poisons, dwell also, the

\footnotetext{
"An important contribution to this discussion is John Wilkins's, Essay Towards Real Character and Philosophical Language (1668).
} 
most potent, salutary virtues: There is some soul goodness in things evil, Would men observingly distil it out. ${ }^{12}$ SHAKESPEARE

(Anderson, A preliminary introduction to the act of sea-bathing, 1795: 8)

Educated authors had received training in Greek and Latin and were familiar with Classical literature, including oratorical devices, and must have enjoyed reading texts written accordingly. Medical doctors belonged to the core of polite society, and thus we can expect some influence from classical education on their writing styles. Several texts exhibit features different from the newly-founded Royal Society writings, but there are also texts that share the characteristics of the interactive dialogic style with imaginary objections and emphathetic replies. For example, the argumentation strategy of James Jurin's seminal work An account of the success of inoculating the small pox in Great Britain (1724) is well in accordance with new science. It contains a reference to Matters-of-Fact, and its statements are straightforward and without "amplifications". The author writes in the first-person singular, guiding his audience with a firm grip. The target group was a community of peers and this community is addressed directly as "every intelligent Reader". The third-person plural they refers to those who doubt or object to the practice of inoculation without proper consideration:

(6) From the Facts here laid down, I am sensible the Inoculators will raise several Objections against the Estimate of the Hazard of Inoculation, which I have given above, and to do them Justice, I am obliged to say what are, or may be their Arguments, before the World.

1. They will maintain that $[\ldots]$

2. They may object, that $[\ldots]$

3. They may justly plead, that $[\ldots]$

4. They may likewise object to [...]

How far these several Objections are of Weight, is submited to the Determination of those, who must and will judge for themselves, that is, to every intelligent Reader, who being thus appriz'd of the Facts, may easily, by striking off such of the Instances given above, as he thinks

${ }^{12}$ Henry V (Act 4 Scene 1). 
reasonable, form to himself a Judgment of the Hazard of Life in this Operation: ...

(Jurin, An account of the success of inoculating the small pox in Great Britain 1724: 37-39)

In this passage, the strategy refers to facts and probabilities, but at the same time it reverts to subtle manipulation. The author appeals directly to his readers' judgement with a speech act that counts as a compliment or even as flattery.

\section{Conclusions}

Our pilot studies have already revealed a diversity of styles and dynamic genre changes in medical writing in the late medieval and early modern periods. As a rule, genres of cutting-edge science exhibit more radical changes than genres with long traditions (see Taavitsainen 2016, 2018). Texts are produced to meet the communicative needs of their users, and language-external facts are needed to interpret how people in the past used texts and genres of writing as meaning-making instruments. Research based on the corpus may cast new light not only on the micro-level of individual linguistic features but also on the macro level of genres, text types and traditions of writing. These three terms refer to groupings made on different bases; keeping these notions apart has proved useful in charting discourse styles of various periods. Genres are functional categories, text types are defined based on text-internal features, and traditions describe texts building on earlier ones in a diachronic line (Taavitsainen 2001a). In addition, genre labels may reveal an ethnographic view of how the community of practice classified the forms of communication, and by this method it is possible to gain a glimpse into eighteenth-century mindsets. ${ }^{13}$ The prevailing genres of the period at the learned end were treatises, essays, and dissertations, ${ }^{14}$ but a great part of medical writing, however, still uses stylistic conventions from the scholastic period, and remedy books, almanacs and regimen texts imparted medical advice in a stable form up to 1800 and beyond. Some texts repeat old received knowledge as such (see Chapter 3 in this

\footnotetext{
${ }^{13}$ We can achieve an insider's view of how contemporary authors attributed texts to genres with the method of "metacommunicative expression analysis", which was developed for speech act studies, but works well for genres, too (see Taavitsainen and Jucker 2007; Taavitsainen 2017). The method is also relevant for historical studies on appropriation.

${ }^{14}$ Meaning 'dispute' (OED): the present meaning is only recent.
} 
volume), but recycled conceptions of humoral theory pop up frequently in the literature of the more popular kind targeted at heterogeneous semiliterate audiences.

To sum up, issues of style and language are multifaceted, and they need to be assessed in an analytical framework taking into account the functions of writing and various audiences. LMEMT enables the sociopragmatic approach, and users of the corpus are encouraged to find out more background facts of text participants and situations of writing. By investigating a broad repertoire of linguistic features of texts with a firm contextual anchoring in the sociohistorical background, we hope to be able to gain insights into the dynamics of writing on different levels. Pertinent research questions include, for example, how the tensions between older and newer styles interplay in various genres, how genres and text types relate to changing thought styles, and how texts targeted at different audiences develop. How authors expressed their public persona in medical texts is another promising area for further research. 